\title{
Acute Flaccid Paralysis with Acute Encephalitis Syndrome at a tertiary care centre of eastern Nepal
}

\author{
Shipra Chaudhary, Rupa Rajbhandari Singh, Nisha Keshary Bhatta, Gauri Shankar Shah, Jyoti \\ Agrawal \\ B P Koirala Institute of Health Sciences (BPKIHS), Dharan, Nepal
}

\section{Correspondence \\ Dr. Shipra Chaudhary \\ Assistant Professor, Department of Paediatrics \& Adolescent Medicine, BPKIHS, Ghopa, Dharan, Nepal \\ Email: \\ shipra.chaudhary@bpkihs.edu}

DOI: http://dx.doi.org/10.3126/ jcmsn.v13i1.16108

Article received: Dec $3^{\text {rd }} 2016$ Article accepted: Jan $25^{\text {th }} 2017$

\begin{abstract}
Background \& Objectives: Acute Flaccid Paralysis (AFP) can have various causes including Acute encephalitis syndrome (AES). Hence this study was done to study the clinical features and outcome of AFP with AES. Materials \& Methods: A Prospective hospital-based study was carried out over one-year period, including all cases fulfilling AFP case definition. All cases of AFP meeting AES definition were further analysed in terms of history, clinical examination, investigations and outcome. Statistical analysis was done using SPSS version 17. Results: Out of total 43 children with AFP, 23 (53.5\%) children had AES. Amongst AFP with AES, altered mental status and seizures were present in $87 \%$ and $74 \%$ respectively. The mean Glasgow Coma Scale (GCS) was 7.61 \pm 3.65 . Predominant weakness pattern was quadriparesis $(87 \%)$. Cerebrospinal fluid was abnormal in $11(47.9 \%)$ children with Japanese encephalitis (JE) positive 8.7\%. Amongst $60.9 \%$ children with complications, respiratory failure $(52.1 \%)$ was the most common. During 60-day follow-up, $11(47.9 \%)$ children expired while $2(8.7 \%)$ still had residual paralysis. Conclusion: AES is one of the common causes of AFP besides other causes. AFP with AES is commonly associated with quadriparesis, low GCS, respiratory complications, neurological sequelae and a high mortality. Thus, this study stresses upon the importance of AES surveillance along with AFP surveillance.
\end{abstract}

Key words: Acute Flaccid Paralysis (AFP); Acute Encephalitis Syndrome (AES); Japanese Encephalitis (JE)

Citation: Chaudhary S, Singh RR, Bhatta NK, Shah GS, Agrawal J. Acute Flaccid Paralysis with Acute Encephalitis Syndrome at a tertiary care centre of eastern Nepal. JCMS Nepal. 2017;13(1):216-9.

\section{INTRODUCTION}

Acute flaccid paralysis (AFP), as defined by Global Polio Eradication Initiative (GPEI), is sudden onset of weakness and floppiness in any part of the body in a child less than 15 years age or when clinician suspects polio in any person of any age (excludes adults, spastic paralysis, old cases or cases with obvious causes like trauma). ${ }^{1}$ The term "flaccid" denotes the absence of spasticity or other signs of disordered central nervous system motor tracts such as hyperreflexia, clonus, or extensor plantar responses. $^{2,3}$

Amongst the various conditions leading to AFP, poliomyelitis has been an important differential. ${ }^{4}$ Since the Global Polio Eradication Initiative by WHO in 1988, Surveillance for AFP is an important public health activity in many countries and polio cases have decreased by over $99 \%{ }^{5}$ With WHO's impressive progress, poliomyelitis is nearing its eradication in the world, other causes of AFP like 
Guillain-Barre syndrome (GBS), transverse myelitis, traumatic paralysis, Vaccine Associated Paralytic Poliomyelitis (VAPP), West Nile virus and other enteroviruses, neurotropic viruses like Rabies, Varicella-zoster, and Japanese Encephalitis have gained importance. Similarly, critical illnesses like polyneuropathy, metabolic disorder like hypokalemic periodic paralysis, polymyositis, neuropathies and neuromuscular junction disorders may also present with AFP. ${ }^{4}$

WHO defines Acute Encephalitis Syndrome (AES) as a person of any age, in any geographical region, at any time of year with the acute onset of fever and a change in mental status (including symptoms such as confusion, disorientation, coma, or inability to talk) and/or new onset of seizures (excluding simple febrile seizures). ${ }^{1}$ Frequently, a child with AES may have AFP which also should be investigated and hence AES surveillance has now been integrated with AFP surveillance so that not a single case of acute flaccid paralysis goes unevaluated and thus helps in polio eradication campaign. ${ }^{1,6}$

AFP can have varied presentation depending upon the underlying cause. ${ }^{4}$ Furthermore, the outcome depends on the severity at presentation and underlying cause. A detail evaluation of child's clinical presentation and thereby proper and timely treatment directly affects the outcome. So, all the differentials of AFP need to be evaluated and AFP with AES should also be considered. . Hence, this study was done to study the clinical features and outcome of AFP with AES in our part.

\section{MATERIALS AND METHODS}

It was a hospital-based prospective study done over one year (Jan 2011-Dec 2011) in the Department of Paediatrics \& Adolescent Medicine, BPKIHS, Dharan. Any child of age $\leq 15$ years presenting with AFP in any form alongwith AES as per WHO definition was included. Children of age $>15 \mathrm{yrs}$, spastic paralysis, old cases or cases with obvious causes like trauma, obvious congenital anomalies or birth defects, AES without acute flaccid paralysis were excluded.

After taking informed consent from caregiver, all children meeting inclusion criteria were enrolled and detail history and clinical examination recorded. Relevant laboratory investigations were performed and stool samples sent for examination as per AFP surveillance guidelines. After instituting treatment, the patients were observed for any complications or sequelae. Regular follow-ups were done after discharge in Paediatrics OPD at 15 days/30 days/60 days along with the help of surveillance team. The stool sample reports were collected from the IPD field office and final classification made according to clinico-laboratory results and subsequent follow-up findings.

The acquired data for all children were entered in SPSS Statistics software version 17 for analysis. Descriptive statistics were used and final inferences made.

\section{RESULTS}

Out of 3432 children admitted during the one-year study period (Jan 2011 to Dec 2011), 43 (1.25\%) children had acute flaccid paralysis. The final classification showed Acute Encephalitis Syndrome (AES) as the most common cause in $23(53.5 \%)$ children.

Amongst the 23 children of AFP with AES, majority, ie 17 (74\%) had high grade fever. Altered mental status was present in $20(87 \%)$ children while seizures in 17 (74\%) children. Other clinical features like headache and vomiting were present in $9(39.1 \%)$ patients each while neck pain was found in $3(13 \%)$.

On clinical examination, the mean GCS was $7.61 \pm 3.65$. One or more signs of meningeal irritation were found in $13 \%$ children. The pattern of weakness in majority, i.e. 20 children of AES with AFP (87\%), was quadriparesis while paraparesis, hemiparesis and monoparesis were found in 1 each. Cranial nerve involvement was seen in $2(8.7 \%)$ children, having bilateral sixth nerve involvement. The deep tendon reflexes were absent or sluggish in 20 (87\%). Sensory and bowel/ bladder involvement were found in $2(8.7 \%)$ and 8 $(34.8 \%)$ respectively. Concurrent underlying paleness and undernutrition were detected in 8 $(34.8 \%)$ and $16(69.6 \%)$ children respectively.

Although lumbar puncture for cerebrospinal fluid (CSF) analysis could not be done in $3(13 \%)$ patients due to hemodynamic instability, 11 (47.9\%) children had abnormal CSF findings with pyogenic meningitis in $2(8.7 \%)$ and viral in rest. Subsequent serology for Japanese encephalitis was positive in $2(8.7 \%)$ and malaria screening was positive in $1(4.3 \%)$. The complications observed and treatment details of the AES children presenting with AFP are shown in table 1.

\section{DISCUSSION}

Acute flaccid paralysis is caused by various diseases, poliomyelitis being one of the most important causes. ${ }^{4}$ Nepal had re-emergence of polio 
Table 1: Treatment details \& complications in children of AFP with AES $(n=23)$

\begin{tabular}{ll|}
\hline Characteristics & No. of patients (\%) \\
\hline ICU requirement & $14(60.9)$ \\
\hline Mechanical ventilation & $11(47.8)$ \\
\hline Steroids & $7(30.4)$ \\
\hline Osmotic diuretic & $12(52.1)$ \\
\hline Inotropes & $19(82.6)$ \\
\hline Complications & $14(60.9)$ \\
Aspiration pneumonitis & $4(17.4)$ \\
Respiratory failure & $12(52.1)$ \\
Autonomic dysfunction & $8(34.8)$ \\
Acute renal failure & $4(17.4)$ \\
\hline $\begin{array}{l}\text { Death by 60-day follow- } \\
\text { up }\end{array}$ & $11(47.9)$ \\
\hline Residual weakness & $2(8.7)$
\end{tabular}

after four years in 2005 and few more imported cases were detected since then. ${ }^{6}$ Acute Encephalitis Syndrome surveillance has also been integrated with AFP surveillance now, so as not to miss any floppy child with AFP. ${ }^{6}$ This study was carried out to study the children presenting with AFP in our part and analyse the cases of AES amongst them.

In our study, the majority $23(53.5 \%)$ children having AES whereas GBS is the main cause of AFP in previous studies. ${ }^{7-11}$ Interestingly, sciatic nerve palsy accounted for majority $(72.0 \%)$ of the AFP in a a five-year review of cases by Hamzat et al. ${ }^{12} \mathrm{Tu}$ YF et $a^{13}$ found that three of 186 paediatric patients with acute bacterial meningitis presented with AFP due to myelopathy. In a study from Vietnam, 55\% of patients identified with AFP were actually later diagnosed with JE. In a previous study of AES at BPKIHS, hypotonia was seen in $25 \%$ of herpetic encephalitis, $7.69 \%$ of non-JE encephalitis, $6.66 \%$ of meningitis and $5.26 \%$ of Japanese Encephalitis. Decreased power was found in $35 \%$ of the acute encephalopathies. ${ }^{14}$

Most of the children, ie 17 (74\%) had high grade fever. Altered mental status was present in 20 (87\%) children while seizures in 17 (84\%) children. Similarly, fever was the most common symptom along with neck rigidity, convulsions, abnormal behavior and seizures in earlier studies. ${ }^{15,16}$ Fever was nearly universal $(92 \%)$ in a study of AFP related to West Nile Virus by Moorman $\mathrm{J}$ et al. ${ }^{17}$ Rayamajhi A et al had found fever ( $>3$ days) in $69 \%$; altered sensorium in $50 \%$; and seizures in $58 \%$ of acute febrile encephalopathy. ${ }^{18}$

The mean GCS in our study was 7.61 \pm 3.65 . More than half $(65.2 \%)$ of the children of AFP with AES had GCS in the range of three to eight. In a study of encephalitis by CR Kennedy et $\mathrm{al},{ }^{19}$ the modified GCS score fell below 11 in $52 \%$ and below six in $12 \%$ patients. Similar findings were also observed in a retrospective study of acute encephalitis syndrome at BPKIHS. ${ }^{18}$ In contrast the median GCS 13 (IQR 10 to 14) with a GCS of $<8$ in 10 (6.7\%) children in a study from Papua New Guinea. ${ }^{20}$ The pattern of weakness in majority $(87 \%)$ was quadriparesis and cranial nerve involvement was seen in two $(8.7 \%)$ children, having bilateral sixth nerve involvement. Singh RR et $\mathrm{al},{ }^{14}$ found neurological deficit in $9.34 \%$ - mostly $7^{\text {th }}$ nerve.

Amongst 11 (47.9\%) children with abnormal CSF findings, there was pyogenic meningitis in two $(8.7 \%)$ and viral meningoencephalitis in rest, of which two had positive JE serology. Similarly, viral encephalitis (46\%) with JE (40\%) was the most common cause in the study by Singh RR et al. ${ }^{14}$ In the study by Karmarkar SA et $\mathrm{al}^{21}{ }^{21}$ pyogenic meningitis was the most frequent diagnosis (33.8 $\%$ while $37.3 \%$ were suspected as viral encephalitis- ( $35.1 \%$.), mumps (10.5\%), Japanese encephalitis (8.7\%), and measles (7\%) cases. Anga G et al. ${ }^{20}$ confirmed S. pneumoniae and H. influenzae as major causes of febrile encephalopathy in children. A study of acute encephalopathy by Kumar et al. ${ }^{22}$ showed pyogenic meningitis and JE to be responsible for $18 \%$ and $12 \%$ of cases, respectively. Khinchi R.et $\mathrm{al}^{23}$ found $\mathrm{JE}$ in $18 \%$ of AES cases with a case fatality of $16.6 \%$. As most patients were referred after initial antibiotics, the yield of pyogenic meningitis could have decreased and not all cases of AES but only those with AFP were enrolled, the proportion of JE could have lowered. Also, there has been decrease in overall cases of JE over last few years after JE vaccination campaigns and inclusion of $\mathrm{JE}$ vaccine in EPI of Nepal.

Although three $(13 \%)$ children expired before collection of stool samples, AFP surveillance was carried out in the rest 20 children, amongst which no virus was isolated and thus it strengthened the 
AFP surveillance. There are no published data of studies of AES with inclusion of stool examination as per AFP surveillance guidelines till now. Inclusion of AES in AFP surveillance has been initiated in Nepal since 2004 so as no case of AFP gets missed. 1,6

Out of 23 children of AFP with AES, 11 (47.9\%) expired while two $(8.7 \%)$ had residual paralysis. In contrast to this, Karmarkar $\mathrm{SA}$ et $\mathrm{al}^{21}$ found significant neurological sequelae in $33.33 \%$ of acute febrile encephalopathy syndrome. In a retrospective study by Rayamajhi A et al., ${ }^{18}$ viral encephalitis had poorer outcome than bacterial (31\% versus 13\%) and JE worse than AES of unknown viral aetiology (48\% versus $24 \%$ ).

\section{CONCLUSION}

AES is one of the common causes of AFP besides other causes. AFP with AES is commonly associated with quadriparesis, low GCS, respiratory complications, neurological sequelae and a high mortality. Thus, this study stresses upon the importance of considering AES surveillance in all cases of AFP so as not a single case of AFP gets missed and thereby AFP with AES gets better diagnosis and management.

\section{REFERENCES}

1. Field Guide for Surveillance of Vaccine Preventable Diseases. Kathmandu, Nepal. Government of Nepal Ministry of Health \& Population Department of Health Services and World Health Organization Programme for Immunization Preventable Diseases (IPD); 2010.

2. Faheem MU, Haroon MZ, Khan AA, Shaukat M, Anwar SA. Acute Flaccid Paralysis Surveillance : A 5 Years Study of Bannu, Pakistan. J Ayub Med Coll Abbottabad. 2015;27 (3):673-6. PMID: 26721037

3. Growdon JH, Fink JS. Paralysis and movement disorder. In: Isselbacher $\mathrm{KJ}$, Braunwald $\mathrm{E}$, Wilson $\mathrm{JD}$, eds. Harrison's principles of internal medicine. New York, NY: McGraw- Hill Book Company, 1994:115-25.

4. Marx A, Glass JD, Sutter RW. Differential Diagnosis of Acute Flaccid Paralysis and Its Role in Poliomyelitis Surveillance. Epidemiol Rev 2000;22 (no. 2):298-316.DOI: 10.1093/oxfordjournals.epirev.a018041. PMID: 11218380.

5. Global Polio Eradication Initiative Annual Report 2012. Geneva: World Health Organization; 2013.

6. Joint National/International Review of Acute Flaccid Paralysis (AFP) Surveillance - Nepal 25 March - 6 April 2006 and 6-12 August 2006. New Delhi. World Health Organization Regional Office for South-East Asia; 2006.

7. Sharma KS, Singh R, Shah GS. Guillain Barre Syndrome; Major Cause of Acute Flaccid Paralysis in Children and Adolescents of Nepal. J Nep Paedtr Soc 2011;31(2):93-97. DOI: 10.3126/jnps.v31i2.4065.

8. Sharma KS, Singh R, Shah GS. Guillain Barre Syndrome Major Cause Of Acute Flaccid Paralysis in Children and Adolescent in Eastern Nepal.;2012;1(2): 39-42.

9. Poorolajal J, Ghasemi S, Farahani LN, Hosseini AS, Bathaei SJ, Zahiri A. Evaluation of Acute Flaccid Paralysis in Hamadan, Iran from 2002 to 2009. Epidemiol Health. 2011;33:e2011011. DOI: 10.4178/epih/e2011011.
PMID: 22111031 .

10. Morris AM, Elliott EJ, D'Souza RM, Antony J, Kennett M, Longbottom H. Acute flaccid paralysis in Australian children. J Paediatr Child Health. 2003 Jan-Feb;39(1):22-6. DOI: $\quad 10.1046 /$ j.1440-1754.2003.00065.x.

PMID: 12542807.

11. McKhann GM, Cornblath DR, Griffin JW, Ho TW, Li CY, Jiang Z, et al.Acute motor axonal neuropathy: a frequent cause of acute flaccid paralysis in China. Ann Neurol. 1993 Apr;33(4):333-42. DOI: 10.1002/ ana.410330402. PMID: 8489203.

12. Hamzat TH, Omotade TT. Acute flaccid paralysis: a fiveyear review of cases managed by physiotherapy at the University College Hospital, Ibadan. Afr J Health Sci. 2006; 13(1-2):28-32. PMID:17348740.

13. Tu YF, Chang YC, Chen CY, Huang CC. Acute flaccid paralysis due to myelopathy in childhood bacterial meningitis. Acta Paediatr Taiwan. 2004 May-Jun;45(3):158 -62. PMID: 15493735

14. Singh RR, Chaudhary SK, Bhatta NK, Khanal B, Shah D. Clinical and etiological profile of acute febrile encephalopathy in eastern Nepal. Indian J Pediatr. 2009 Nov;76(11):1109-11. DOI: 10.1007/s12098-009-0233-8. PMID: 20012797.

15. Zangwill KM, Yeh SH, Wong EJ, Marcy SM, Eriksen E, Huff KR,et al. Paralytic Syndromes in Children: Epidemiology and Relationship to Vaccination. Pediatr Neurol. 2010 Mar;42(3):206-12. DOI: 10.1016/ j.pediatrneurol.2009.10.012. PMID: 20159431.

16. Borah J, Dutta P, Khan SA, Mahanta J. A comparison of clinical features of Japanese encephalitis virus infection in the adult and pediatric age group with Acute Encephalitis Syndrome. J Clin Virol. 2011 Sep;52(1):45-9. DOI: 10.1016/j.jcv.2011.06.001. PMID: 21715224.

17. Saad M, Youssef S, Kirschke D, Shubair M, Haddadin $\mathrm{D}$, Myers $\mathrm{J}$ et al. Acute flaccid paralysis: the spectrum of a newly recognized complication of West Nile virus infection. J Infect. 2005 Aug;51(2):120-7. Epub 2004 Nov 6. DOI: 10.1016/j.jinf.2004.10.005. PMID:16038762.

18. Rayamajhi A, Singh R, Prasad R, Khanal B, Singhi S. Study of Japanese encephalitis and other viral encephalitis in Nepali children. Pediatr Int. 2007 Dec;49(6):978-84. DOI: $\quad 10.1111 /$ j.1442-200X.2007.02495.x.

PMID: 18045307.

19. Kennedy CR, Duffy SW, Smith R, Robinson RO.Clinical predictors of outcome in encephalitis. Arch Dis Child. 1987 Nov;62(11):1156-62. DOI: $10.1136 /$ adc.62.11.1156. PMID: 3688920.

20. Anga G, Barnabas R, Kaminiel O, Tefuarani N, Vince J, Ripa $P$ et al. The aetiology, clinical presentations and outcome of febrile encephalopathy in children in Papua New Guinea. Ann Trop Paediatr. 2010;30(2):109-18. DOI: 10.1179/146532810X12703902243818. PMID: 20522297.

21. Karmarkar SA, Aneja S, Khare S, Saini A, Seth A, Chauhan BK. A study of acute febrile encephalopathy with special reference to viral etiology. Indian J Pediatr. 2008 Aug;75(8):801-5. Epub 2008 Sep 4. DOI: 10.1007/s12098-008-0150-2. PMID: 18769890.

22. Kumar R, Mathur A, Kumar A, Sethi GD, Sharma S, Chaturvedi UC. Virological investigations of acute encephalopathy in India. Arch Dis Child 1990; 65: 12271230. DOI: 10.1136/adc.65.11.1227. PMID: 2174227.

23. Khinchi YR, Kumar A, Yadav S. Study of acute encephalitis syndrome in children. JCMS Nepal. 2010; 6 (1):7-13. DOI: $10.3126 / \mathrm{jcmsn} . v 6 \mathrm{i} 1.3596$. 